\title{
A EFICÁCIA DO DEPOIMENTO ESPECIAL NA BUSCA PELA PROTEÇÃO À INTEGRIDADE PSICOLÓGICA DE CRIANÇAS E ADOLESCENTES VÍTIMAS DE VIOLÊNCIA SEXUAL
}

\section{THE EFFECTIVENESS OF SPECIAL STATEMENT IN SEARCH FOR THE PROTECTION OF THE PSYCHOLOGICAL INTEGRITY OF CHILDREN AND ADOLESCENTS VICTIMS OF SEXUAL VIOLENCE}

\author{
Taianara Nardelli ${ }^{1}$
}

Resumo: O presente artigo busca examinar se o depoimento especial é eficaz na busca pela proteção à integridade psicológica de crianças e adolescentes vítimas de violência sexual. Sabe-se que o crime de violência sexual traz inúmeras consequências, especialmente para crianças e adolescentes que ainda se encontram em estado de desenvolvimento. Neste sentido, originou-se um projeto, inicialmente chamado de 'depoimento sem dano', que resultou na promulgação da Lei n. $13.431 / 17$, a qual objetiva reduzir a vitimização causada pela inquirição em juízo e facilitar o entendimento pela vítima acerca da necessidade de explicitar de forma clara e verdadeira o ilí- cito ocorrido, com a utilização de profissionais especializados para tanto. $\mathrm{O}$ projeto é fruto de inúmeros estudos que trazem essa metodologia de inquirição menos danosa e mais garantista de direitos, visando sua dignidade e integridade, e concomitantemente, o auxílio na busca pela verdade. O método de abordagem utilizado na elaboração desse artigo foi o indutivo. O levantamento de dados foi através da técnica da pesquisa bibliográfica. O ramo de estudo é na área do Direito Penal e Processual Penal.

Palavras-chave: Depoimento especial. Violência sexual. Crianças e adolescentes. Inquirição em juízo.

1 Graduada em Direito pelo Centro Universitário para o Desenvolvimento do Alto Vale do Itajaí (Unidavi); estudante da Escola Superior da Magistratura do Estado de Santa Catarina (Esmesc). E-mail: taianaranardelli@hotmail.com. 
Abstract: This article seeks to examine whether special statement is effective in seeking to protect the psychological integrity of children and adolescents who are victims of sexual violence. It is known that the crime of sexual violence has many consequences, especially for children and adolescents who are still in a state of development. In this sense, a project was born, initially called "statement without damage", which resulted in the enactment of Law 13.431/17, which aims to reduce victimization caused by Court inquiries and facilitate the victim's understanding of the need to make explicit in a clear and true way the illicit occurred, with the use of specialized professionals to do so. The project is the result of numerous studies that brings this methodology of inquiry less harmful and more guaranteeing rights, aiming at their dignity and integrity, and concomitantly, aid in the search for the truth. The method used in the elaboration of this article was the inductive method. The data collection was through the technique of bibliographic research. The field of study is in the area of Criminal Law and Criminal Procedure.

Key Words: Special Statement. Sexual Violence. Children and Adolescents. Inquiry in Court.

\section{INTRODUÇÃO}

O presente estudo tem como objetivo principal investigar a eficácia do depoimento especial na busca pela proteção à integridade psicológica de crianças e adolescentes vítimas de violência sexual, tendo em vista a recente promulgação da Lei n. 13.431, de 04 de abril de 2017.

O crime de violência sexual cometido contra crianças e adolescentes é um grande paradigma da sociedade que envolve dois lados: um deles, a pressão popular de achar o criminoso, na ânsia por fazer justiça, e do outro, a preocupação com o desenvolvimento psicológico saudável da vítima, com respeito a sua dignidade e integridade, bem como precaução com o impacto causado pela violência.

Nesse sentido, o modo com que o processo penal brasileiro dispõe acerca da oitiva das crianças e adolescentes vítimas de violência sexual em juízo, é de suma importância, diante das possíveis implicações psicológicas causadas quando da sua inquirição sobre a violência sexual. Isso porque, inúmeras são as 
sequelas decorrentes do delito, como, por exemplo, a vitimização, a síndrome do segredo e o fenômeno das falsas memórias.

Tendo como base essas ideias, o projeto inicial do 'depoimento sem dano' e a atual Lei n. 13.431/17 que trouxe como nomenclatura 'depoimento especial', originaram uma solução viável para o paradigma social da aplicação da lei penal para o criminoso e a oitiva da vítima de violência sexual, na busca por um método que se preocupe com sua integridade psicológica, já que se tratam de pessoas em condição de desenvolvimento e necessitam de maior proteção.

Acerca da metodologia utilizada para o desenvolvimento deste artigo, menciona-se que o método de abordagem é o indutivo, sendo que o levantamento de dados foi por meio da técnica de pesquisa bibliográfica.

\section{A VIOLÊNCIA SEXUAL PRATICADA CONTRA CRIANÇAS E ADOLESCENTES}

O abuso sexual praticado contra crianças e adolescentes possui grande repercussão na sociedade por se tratar de um fato que enseja graves consequências no desenvolvimento intelectual, pessoal e social da vítima.

Na visão de Gonçalves e Brandão (2015, p. 304), a definição de violência sexual infantojuvenil deve ser avaliada de uma forma mais ampla, com a perspectiva de que "os atos designados como abuso ou violência sexual podem ou não envolver contato físico com a criança; por isso, não se deve esperar que essa modalidade de violência apresente, necessariamente, um sinal corporal visível".

Ressalta-se que a violência sexual infantojuvenil passou a ser considerada de grande relevância no Brasil a partir da publicação do Estatuto da Criança e do Adolescente (Lei n. 
8.069/90), da qual o Estado assumiu a tutela e desenvolveu uma proteção especial para as crianças e adolescentes vítimas de abuso sexual (TRINDADE, 2014). Dessa forma, dispõe o art. $5^{\circ}$ do ECA, in verbis:

Art. $5^{\circ}$. Nenhuma criança ou adolescente será objeto de qualquer forma de negligência, discriminação, exploração, violência, crueldade e opressão, punido na forma da lei qualquer atentado, por ação ou omissão, aos seus direitos fundamentais. (BRASIL, 1990, p. 1).

Extrai-se, nesse sentido, a concretização da imprescindibilidade de proteção à dignidade da pessoa humana em estado de desenvolvimento. Com esse enfoque é que se discorre, em todo o Estatuto, instrumentos capazes de amparar essa fase de desenvolvimento da vida humana. Assim, torna-se dever da família, do Estado e da sociedade assegurar à infância e a juventude o direito ao crescimento pessoal e intelectual. Entretanto, muitas vezes são esses protagonistas os agentes causadores de violências contra crianças e adolescentes (CASTRO, 2008).

\section{A OITIVA EM JUÍZO E SEU VALOR PROBATÓRIO}

Quando o assunto diz respeito à oitiva de crianças e adolescentes vítimas de violência sexual, deve-se ater que o valor da prova testemunhal nos crimes de abuso sexual assume grande relevância diante da sua clandestinidade. Por outro lado, "deve-se exigir maior sensibilidade do julgador nesses casos, pois depoimentos de crianças acarretam alta sugestionabilidade e falsas memórias, devendo ter uma posição de maior rigidez no julgamento e colheita de depoimentos desses processos" (DEEKE, 2016).

Na perspectiva de Ribeiro (2012, p. 95-96), a comprovação da materialidade em crimes que apuram a violência sexual não 
é uma tarefa fácil, tendo em vista a não existência de vestígios ou a constatação apenas da prática de determinado ato sexual, sem a retratação da presença de violência, por exemplo. Ressalta ainda, que há uma questão que merece atenção: "a vítima é parte integrante do evento criminoso, não é neutra, distante; pelo contrário, está diretamente envolvida e interessada, motivo pelo qual a atribuição de absoluta prevalência à sua palavra [...] pode tornar a "verdade" cada vez mais intangível".

Sendo assim, visualizando toda essa problemática na inquirição de crianças e adolescentes vítimas de violência sexual Tourinho Filho (2010, p. 599) afirma que "o depoimento de uma criança deve ser aceito quando seus relatos guardam coerência, são harmônicos com o restante das provas e encontram apoio em depoimentos de testemunhas adultas".

Esse mesmo entendimento é seguido pelas instâncias superiores:

PENAL E PROCESSO PENAL. AGRAVO REGIMENTAL NO RECURSO ESPECIAL. CRIME CONTRA OS COSTUMES. ANTERIOR ATENTADO VIOLENTO AO PUDOR. VÍTIMA MENOR DE 14 ANOS. PEDIDO DE ABSOLVIÇÃO. IMPOSSIBILIDADE. PALAVRA DA VÍTIMA CORROBORADA POR OUTROS ELEMENTOS DE PROVA. REEXAME FÁTICO-PROBATÓRIO. SÚMULA 7/STJ. [...] 2. A jurisprudência desta Corte é no sentido de que, em razão das dificuldades que envolvem a obtenção de provas de crimes contra a liberdade sexual - praticados, na maioria das vezes, longe dos olhos de testemunhas e, normalmente, sem vestígios físicos que permitam a comprovação dos eventos - a palavra da vítima adquire relevo diferenciado.3. Agravo regimental não provido. (STJ, AgRg no REsp 1774080/RS).

Portanto, é visível que a vítima de violência sexual passa por vários problemas psicológicos e emocionais que podem interferir no seu depoimento, sem ao menos perceber. Com isso, 
deve o magistrado ter a cautela de averiguar todo o conjunto probatório e analisar se o depoimento merece respaldo.

\section{IMPLICAÇÕES PSICOLÓGICAS ACERCA DA INQUIRIÇÃO SOBRE A VIOLÊNCIA SEXUAL}

Um dos aspectos mais importantes para se destacar acercados depoimentos de crianças e adolescentes vítimas de violência sexual são as lesivas consequências causadas por este ato. Ao encerrar a inquirição tradicional, a situação de aflição da vítima não termina devido à distância existente entre a formalidade do ato judicial e a realidade dos fatos.

$\mathrm{Na}$ tentativa de minimizar os efeitos negativos causados pela tomada de depoimento durante a instrução penal, a Lei n. 11.690/2008 incluiu ao art. 201 do CPP o parágrafo $5^{\circ}$, que possui a seguinte redação:

Art. 201. Sempre que possível, o ofendido será qualificado e perguntado sobre as circunstâncias da infração, quem seja ou presuma ser o autor, as provas que possa indicar, tomando-se por termo as suas declarações. [...] § $5^{\circ}$ Se o juiz entender necessário, poderá encaminhar o ofendido para atendimento multidisciplinar, especialmente nas áreas psicossocial, de assistência jurídica e de saúde, a expensas do ofensor ou do Estado. (BRASIL, 1941, p. 24).

Machado (2016) explica que essa previsão de tomada de providências pelo juiz está voltada à preservação da intimidade, honra e imagem da vítima. Entretanto, não se tem notícias da criação de um programa de acolhimento de vítimas de crime pelo Estado. Sendo assim, a lei faculta ao magistrado o encaminhamento do ofendido para atendimento por equipe multidisciplinar, mas o próprio poder público se omite e impede essa atuação.

Seguindo essa dinâmica, inúmeros são os problemas psi- 
cológicos enfrentados pelas vítimas de violência sexual, dentre os quais se destacam: vitimização, síndrome do segredo e falsas memórias.

\subsection{Vitimização}

A vitimização é um processo da qual uma pessoa sofre, direta ou indiretamente, consequências negativas oriundas de um fato traumático, geralmente decorrente de um crime. Nesse aspecto, Barros (2008, p. 73) informa que a vitimização se principia no momento do cometimento da ação, seguida da fase investigativa do inquérito policial e percorre todas as etapas do processo penal.

Nos crimes sexuais cometidos contra crianças e adolescentes, a vitimização transparece na exposição das vítimas a estímulos sexuais impróprios para sua idade, já que sua personalidade está em desenvolvimento. Dessa forma, sua dignidade apresenta-se constantemente atacada pela sociedade, família e instituições (POTTER; BITENCOURT, 2009, p. 43).

Os doutrinadores classificam a vitimização em três graus: primária, secundária e terciária. A vitimização primária é ocasionada pelo próprio crime, isto é, na própria experiência do abuso, em que o agente viola os direitos da vítima (MOROTTI, 2015). Desse modo, está expressada no momento em que o agressor, prevalecendo da superioridade, obriga a vítima infantojuvenil, por intermédio de força física ou por pressão moral, a participar de relações sexuais.

A vitimização secundária é decorrente dos próprios métodos utilizados pelo sistema judiciário, visto a formalidade com que o poder estatal trata a condição frágil da criança ou adolescente ao abordar sobre a violência sexual. Segundo Niza e Silva (2018), essa espécie de vitimização pode "se concretizar por meio de um tratamento desrespeitoso por parte das autori- 
dades com a vítima, da demora no processamento do feito, das cerimônias degradantes a que são submetidas as vítimas".

Finalmente, a vitimização terciária é visualizada quando essa absorve a vitimização primária e secundária e, com isso, utiliza-se dessas experiências para se relacionar com os semelhantes, entretanto, com um sentimento vingativo, já que sua mente está consumida pelas vivências negativas. Na explicação de Queiroz (2019), a vitimização terciária manifesta-se após as fases pré-processual e processual, da qual, em suas palavras: "não bastasse todas as circunstâncias já experimentadas pela vítima nos graus primário e secundário, ainda se tem o mais duradouro processo de vitimização".

\subsection{Síndrome do segredo}

Ao estudar a violência sexual sofrida por crianças e adolescentes, lembra-se que muitas vítimas se mantêm caladas ou ocultam as verdades dos fatos por um longo período de tempo. Esse acontecimento é chamado pelos psicólogos como síndrome do segredo, isto é, a motivação que leva a criança a não revelar o abuso e que podem ser descritos de diversas formas, como, por exemplo, a culpa que a criança sente por ter participado da interação abusiva, ou as consequências que se dará sob a revelação, entre elas a desintegração familiar (BORBA, 2002).

Esta síndrome "está diretamente relacionada com a psicopatologia do agressor que, por gerar intenso repúdio social, tende a se proteger em uma teia do segredo, mantido à custa de ameaças e barganhas à criança abusada". (HABIGZANG; KOLLER; AZEVEDO; MACHADO, 2005, p. 342). Dessa forma, a criança sendo coagida por promessas mentirosas e estando cercada pelo medo, permanece calada perante a situação. Esse fenômeno é caracterizado "como um dos principais obstáculos à investigação e trâmite processual relativas ao de- 
lito" (POTTER; BITENCOURT, 2009, p. 21).

Cezar (2007, p. 47) destaca o fator da distorção da realidade, referindo-se à "manipulação, pelo abusador, da realidade da criança de modo que esta sinta que é a abusadora e ele a vítima, alterando psicologicamente os papéis que cada um exerce na ação".

Além disso, a preservação do segredo está relacionada a diversos medos, além daqueles provenientes de ameaças. Existem as consequências da revelação no que tange a falta de credibilidade que lhe pode ser imposta, já que a criança perde a confiança nos adultos e tende a crer que sua palavra será desvalorizada frente a eles, posteriormente (GABEL, 1997, p. 55).

Todos esses fatores descritos levam a três possíveis mecanismos de defesa por parte da criança: a mentira, a negação e a dissociação. As crianças e adolescentes mentem sobre o abuso sexual, por medo de serem castigadas e não serem protegidas, além do medo de ninguém acreditar na sua revelação (GABEL, 1997, p. 31). A negação está presente na "ausência da consciência do fato abusivo pela criança ou seus familiares, criando-se uma estrutura negadora de realidade da experiência" (DOBKE, 2011, p. 35). Já a dissociação é método no qual a vítima separa o abuso sexual (fato real) dos sentimentos que $o$ ato the provoca (DOBKE, 2011, p. 35).

\subsection{Falsas memórias}

Importante destacar ainda, o fator das falsas memórias que podem influenciar o depoimento de crianças e adolescentes e que devem ser levados em conta no momento da valoração da prova. Essas falsas memórias são definidas como lembranças relacionadas a eventos que nunca ocorreram. Assim, destaca Seger (2012, p. 8):

Os atuais questionamentos referentes à habilidade de crian- 
ças e adultos - sejam eles depoentes como vítimas de abuso físico (ou sexual) ou como testemunhas oculares de crimes e contravenções em geral - de relatar fidedignamente os fatos vividos têm aberto as portas para o estudo científico das falsas memórias, que constituem, resumidamente, um fenômeno cujo efeito é nos lembrarmos de eventos que, na realidade, não ocorreram.

A memória, neste contexto, é disposta para as pessoas como uma fonte de segurança acerca da certeza do que é conhecido, isto é, as ações humanas e a percepção do mundo é constituída em lembranças. No entender de Masi (2015), “as memórias humanas são feitas, armazenadas e evocadas por redes de células nervosas (neurônios), sendo, portanto, moduláveis pelas emoções, pelo nível de consciência e pelos estados de ânimo".

Dessa forma, observa-se que as pessoas, ao vivenciarem uma situação, focam apenas em alguns aspectos relacionados ao evento. Sendo assim, não armazenam na memória todas as informações desse acontecimento e ao tentar relembrar o fato que está registrado em sua mente, torna-se impossível recordar todos os detalhes que ocorreram. Com isso, o indivíduo pode acrescentar novos dados às lembranças, isto é, falsas memórias (STEIN, 2010, p. 210).

Essas falsas memórias são mais suscetíveis de serem criadas por crianças, tendo em vista que são mais propensas a sugestões externas. Com isso, indivíduos podem incorporar informações distorcidas, intencional ou acidentalmente, as recordações que de fato estão na mente da criança (DEEKE, 2016).

Nesse sentido, denota-se que o depoimento de crianças e adolescentes vítimas de violência sexual estão sujeitos a várias interferências psicológicas. As falsas memórias, a síndrome do segredo e a vitimização são exemplos claros das consequências que o trauma da violência e demonstram o quão importante é a cautela na hora da colheita de provas. 
Entretanto, há estudos que revelam que o depoimento especial se apresenta como uma alternativa eficiente para solucionar esses problemas oriundos da violência sexual, na busca pela verdade com efeito menos danoso para a vítima.

\section{PROJETO DEPOIMENTO SEM DANO}

O projeto depoimento sem dano é a "denominação dada a um método de oitiva de crianças e adolescentes em Juízo, isto é, em processos judiciais, diverso do modo constante no Código de Processo Penal". (ROQUE, 2010, p. 85). O projeto se desenvolveu a partir da necessidade de solucionar as dificuldades suportadas por magistrados, promotores e advogados ao se relacionarem profissionalmente com crianças e adolescentes vítimas de violência sexual, tendo em vista a falta de base formativa para tal interação.

Tal método foi idealizado e instituído pelo juiz José Antônio Daltoé Cezar na $2^{\mathrm{a}}$ Vara da Infância e Juventude de Porto Alegre, Rio Grande do Sul, em maio de 2003. A respeito do assunto, Benjamin (2006) destaca:

Experiência pioneira no Brasil, o projeto "Depoimento sem

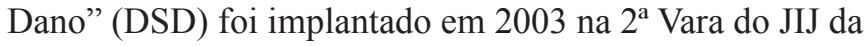
Capital, com o objetivo de promover a proteção psicológica das vítimas, permitindo a realização de instrução criminal tecnicamente mais apurada. O DSD prevê a possibilidade de produção antecipada de prova no processo penal, antes do ajuizamento da ação, para evitar que a criança seja revitimizada com sucessivas inquirições nos âmbitos administrativo, policial e judicial. A sistemática permite a realização de audiência, simultaneamente, em duas salas interligadas por equipamentos de som e imagem. Em recinto reservado, a vítima presta depoimento a uma Psicóloga ou Assistente Social. Na sala de audiências ficam Juiz, Promotor, Advogado e partes. O magistrado faz as inquirições por intermédio do profissional que se encontra com a vítima que, dessa forma, não se expõe a outras pessoas. Simulta- 
neamente é efetivada a gravação de som e imagem em CD, que é anexado aos autos do processo judicial.

De acordo com esse modelo, as crianças e adolescentes vítimas de violência sexual deverão ser inquiridas em uma sala especial situada nas dependências do Fórum, projetada de modo aconchegante para que a vítima se sinta acolhida, além de ser utilizado câmeras e microfones para a gravação do depoimento. Dessarte, o psicólogo ou assistente social permanecerá com fones de ouvido para que o juiz possa realizar os questionamentos necessários, e assim, o profissional irá indagar a criança de modo que ela possa responder sem causar abalo psicológico (BRITO, 2008).

Nota-se que a inovação trazida pelo projeto se baseia no procedimento a ser adotado diante da coleta do depoimento das crianças e adolescentes vítimas de violência sexual, posicionando-se no sentido de ser realizado por profissionais especializados em lidar com esse tipo de situação, na busca por um tratamento mais adequado e menos prejudicial a vítima.

\subsection{Acolhimento inicial, depoimento propriamente dito e acolhimento final}

Ao tratar acerca da metodologia utilizada pelo depoimento sem dano, a doutrina separa em três fases: acolhimento inicial, depoimento propriamente dito e acolhimento final.

O acolhimento inicial consiste na intimação do responsável pela criança ou adolescente para que compareça na audiência, com antecedência de quinze a trinta minutos. Neste momento, a pessoa de sua confiança e o menor serão acolhidos por um técnico, sendo inteirados do procedimento (CEZAR, 2007, p. 68).

Essa fase inicial objetiva evitar o encontro entre a criança e o suposto autor da violência, "pois constata-se que quando 
esse encontro ocorre, mesmo que rapidamente, as crianças e adolescentes restam abalados psicologicamente, o que prejudica diretamente a oitiva, gerando depoimentos dúbios e inconsistentes" (CEZAR, 2007, p. 68).

A respeito da importância dessa fase inicial, destaca Trindade (2009, p. 174-175):

No primordial interesse da criança e para a sua própria proteção, que deve ser integral, e sendo o depoimento uma prova de particular relevo, é indispensável, antes de tudo, sob pena de inquinamento da prova em si mesmo e a consequente inutilização das declarações, a avaliação da capacidade da criança, não apenas no aspecto cognitivo (memória, linguagem, inteligência, etc.), mas também no nível afetivo (a dinâmica interna da criança frente a uma eventual confirmação dos fatos). Tais condições são importantes na coleta do depoimento infantil e na sua avaliação, bem como na compreensão dos limites que ela pode apresentar.

Após a fase do acolhimento inicial, dar-se-á início a audiência de instrução e julgamento propriamente dita. Esta etapa é aquela decorrente das próprias determinações do CPP. Assim, no depoimento sem dano a forma processual vigente não diverge da comumente utilizada, considerando que compete ao juiz "dar início e ordenar aos atos, conforme a lei, e decidir sobre as questões que forem suscitadas durante o seu transcorrer - cabendo ao técnico atuar como facilitador do depoimento da criança" (TABAJASKI; PAIVA; VISNIEVSKI, 2010, p. 65).

Nesta fase, a presença do especialista é vista com o propósito de facilitar o acesso aos entendimentos do menor, com intuito de obter respostas lógicas e verdadeiras aos fatos alegados. Neste contexto, Daltoé Cezar (2007, p. 70) afirma:

Os operadores do Direito, na hipótese de não se encontrarem capacitados para a inquirição da criança abusada, de não terem conhecimento sobre a dinâmica do abuso sexual ou de não entenderem a linguagem das pequenas vítimas, 
podem nomear um intérprete, com formação em psicologia e capacitação da problemática do abuso sexual para, através dele, ouvir a criança numa tentativa de melhor atingir os objetivos da ouvida-não infligir dano secundário e obter relato que possa ser validado como prova para a condenação, se for o caso.

No que tange a própria inquirição, esta ocorre em uma sala separada da sala de audiências, na qual há uma ligação de vídeo, áudio e ponto eletrônico, da qual o juiz faz as perguntas, tanto da acusação quanto da defesa, ao profissional intérprete que, por sua vez, transmitirá, de modo pertinente com o vocabulário averiguado no acolhimento inicial, à criança ou adolescente (OLIVEIRA, 2005, p. 120-121). Com isso, a íntegra do depoimento é gravada e juntada aos autos para que as partes e o magistrado possam rever o depoimento a qualquer tempo, além dos desembargadores, em caso de recurso (CEZAR, 2007, p. 62).

A fase que conclui o procedimento do depoimento sem dano é a conhecida como acolhimento final da vítima. Esta etapa, diferente do que ocorre no processo judicial comum, "não há intuito de cessar todo o contato do sistema com a criança, mas sim manter os cuidados sobre esta, valorizando-a como sujeito de direitos" (AZEVEDO, 2013, p. 41).

Esta fase prevê a permanência do técnico com a criança ou adolescente e sua família ao final da audiência, durante uma média de trinta minutos e com o sistema de gravação desligado, para a coleta de assinaturas e a realização de comentários acerca da audiência (CEZAR, 2008).

Este período também está reservado ao profissional para as intervenções que achar necessário, como o encaminhamento da criança ou adolescente "junto à rede de proteção, podendo ainda conversar a respeito dos sentimentos de tristeza, raiva, culpa, vergonha etc., e identificar através desses aspectos, como a família está gerenciando os conflitos familiares" (CE- 
ZAR, 2008).

Para pôr fim a esta etapa, "é comum proceder-se à retomada de assuntos mais neutros, objetivando que as pessoas ali expostas possam retirar-se da situação judicial em um estado emocional mais positivo" (AZEVEDO, 2013, p. 41).

Dessa forma, a lei, que possui reflexos no depoimento sem dano, visa se tornar uma medida auxiliar no processo de formação da conviç̧ão do juiz, na busca pela atuação como ferramenta na produção de prova antecipada, promovendo ainda a proteção psicológica da criança ou adolescente (SOUSA, 2012).

Além disso, destaca Lima (2018, p. 712) que:

[...] haverá evidente restrição à publicidade do ato processual, justificada pelo dever estatal de proteção às testemunhas [...] No caso de depoimentos de vulneráveis, o interesse social caracteriza-se pela necessária proteção à integridade física, psíquica e emocional da testemunha, considerada sua condição peculiar, assim como pela necessidade de evitar a revitimização do depoente, ocasionada por sucessivas inquirições sobre o mesmo fato delituoso, seja na fase investigatória, seja na fase processual.

Sendo assim, denota-se que a lei visa a proteção do menor abusado a fim de evitar constrangimento de se expor pública e repetidamente a situação traumatizante (AZAMBUJA, 2012). Seguindo essa dinâmica, estariam assegurados os direitos inerentes às crianças e adolescentes de prioridade estatal.

\section{DEPOIMENTO ESPECIAL INTRODUZIDO PELA LEI N. 13.431/17}

Tendo como base o referido projeto, em 4 de abril de 2017 foi sancionada a Lei n. 13.431/17 o qual estabeleceu um método que visa garantir os direitos de crianças e adolescentes vítimas e testemunhas de violência, por meio do chamado de- 
poimento especial. "A medida reconhece projeto que começou na Justiça do Rio Grande do Sul e consiste em uma das principais ferramentas de trabalho para operadores do direito que atuam em casos de violência contra crianças e adolescentes" (CNJ, 2017).

Segundo Lima (2018, p. 711) a lei objetivou "resguardar crianças ou adolescentes vítimas ou testemunhas de violência de qualquer contato, ainda que visual, com o suposto ator ou acusado, ou até mesmo com outra pessoa que represente ameaça, coação ou constrangimento".

Na visão de Gonçalves (2018, p. 312):

As especificidades da forma de colheita do depoimento destinam-se a oferecer proteção integral a menores que estejam em condição de vítima ou de testemunha, por meio de mecanismos que inibam a "revitimização", termo empregado para designar os danos psicoemocionais causados adicionalmente ao ofendido pela investigação ou pelo processo judicial em decorrência de indevida exposição de sua intimidade, de colheita de múltiplos depoimentos, de tratamento inadequado por ocasião da inquirição, de contato direito com o agressor etc.

A fim de evitar a revitimização praticada contra as vítimas infantojuvenis, a lei consagra duas figuras diversas de procedimento para sua oitiva: a escuta especializada e o depoimento especial. Tais institutos são destacados na própria lei como sendo:

Art. $7^{\circ}$. Escuta especializada é o procedimento de entrevista sobre situação de violência com criança ou adolescente perante órgão da rede de proteção, limitado o relato estritamente ao necessário para o cumprimento de sua finalidade.

Art. $8^{\circ}$. Depoimento especial é o procedimento de oitiva de criança ou adolescente vítima ou testemunha de violência perante autoridade policial ou judiciária (BRASIL, 2015, p. 3). 
Além disso, determina a lei que o depoimento especial seguirá o rito cautelar de antecipação da prova quando a criança tiver menos de 07 (sete) anos ou em casos de violência sexual (artigo 11, § $1^{\circ}$ ).

Cabe ressaltar ainda, conforme preconiza Lima (2018, p. 711) que "tanto a escuta especializada quanto o depoimento especial deverão ser realizados em local apropriado e acolhedor, com infraestrutura e espaço físico que garantem a privacidade da criança ou adolescente vítima ou testemunha de violência".

Essa sala projetada para a oitiva, no entender dos especialistas, é extremamente importante, para dinamizar a visão da criança ou adolescente, tornando um ambiente mais aconchegante para quem já passou por inúmeros constrangimentos. Nesses termos, Roque (2010, p. 95) ensina:

Embora pareça, numa análise superficial, simples e sem relevância, o ambiente no qual se insere a criança ou adolescente a ser ouvida num processo judicial influi em muito no seu estado emocional e psicológico, acarretando consequências tanto negativas quando positivas à própria eficácia do depoimento. Destarte, cediço que o ambiente relacionado ao Poder Judiciário - tribunais e fóruns em geral, e suas salas de audiência, vinculam-se a características de sobriedade, seriedade e formalidade. Se, para os leigos, o significado de "estar perante o juiz" remete à ansiedade, nervosismo e stress, quanto mais para crianças e adolescentes. De suma importância, assim, a adequação do espaço físico para receber o depoente, a fim de propiciar ambiente que transmita, na medida do possível, segurança e conforto para enfrentar a entrevista.

Neste sentido, na busca pela preservação à integridade psicológica das crianças e adolescentes vítimas de violência sexual a metodologia traz a realização da coleta da oitiva por meio de profissionais especializados. Com base nisso, Digiácomo (2018, p. 6) acrescenta ainda que o depoimento será realizado: 
[...] por profissionais qualificados, em local adequado e respeitando o "tempo" e os desejos e opiniões da criança/ adolescente ( $\operatorname{art} .5^{\circ}$ ), passando a escuta perante a autoridade policial ou judiciária a ser reconhecida como um direito daquela, e não uma obrigação.

No tocante aos profissionais especializados, Menegazzo (2011) destaca que estes devem estudar o processo, o meio social no qual ocorreu o delito, bem como procurar conhecer o âmbito familiar onde a vítima está inserida, além de "ser capacitado para, através da escuta da criança e/ou do adolescente, extrair os dados necessários sem causar danos psíquicos ao entrevistado".

Para atender a essas demandas, Daltoé (2007, p. 72) enumera algumas características necessárias no profissional, tais como: "habilidade em ouvir, empatia, paciência, disposição para acolhimento, bem como capacidade para deixar o depoente o mais à vontade possível durante a audiência".

Nesse sentido, visualiza-se se que a proposta da lei é de evitar que as crianças e adolescentes sejam prejudicadas no momento da inquirição em juízo. Para tanto, defende-se que "a humanização do Judiciário é [...] parte essencial e motivadora da metodologia desenvolvida" (MÖLLER; DINIZ, 2018, p. 16).

\section{CONCLUSÃO}

Observa-se que a criminalidade vem crescendo gradativamente, e, por consequência, o afogamento do Poder Judiciário frente aos inúmeros processos que devem ser analisados individualmente. Com isso, torna-se obrigação do magistrado solucionar, de maneira justa e célere, os mais variados casos objetivando, acima de tudo, que os cidadãos se sintam amparados pelo sistema penal. 
Dessa forma, surge a pressão popular na busca pela solução dos ilícitos penais, incluindo-se, de um lado, a vítima e seus familiares que sentem a necessidade de fazer justiça e o Estado que procura demonstrar o cumprimento de seu papel. Do outro lado, encontra-se o suposto criminoso e sua família, que também possuem direitos a serem amparados e cumpridos.

Entretanto, ao analisar o crime de violência sexual cometido contra crianças e adolescentes, visualiza-se que existe uma terceira figura, isto é, a necessidade de proteção à vítima que necessita de assistência para enfrentar suas angústias e medos. Diante disso, torna-se dever do Estado a conciliação entre os paradigmas propostos, visando prover uma solução justa.

Nota-se que nesses crimes é imprescindível o auxílio da criança ou adolescente para relatar o ocorrido e auxiliar na investigação judicial, visto que, na maioria dos casos, a única testemunha é a própria vítima. No entanto, essa necessidade pode causar abalos psicológicos, como a revitimização, isto é, o relato diante de uma lembrança ruim pode causar repetido sofrimento a vítima.

Além disso, ao narrar detalhadamente a situação, a criança ou adolescente está propícia a ocorrência da síndrome do segredo, em que permanece calado, visto que cria uma defesa pessoal diante da circunstância e, possivelmente, o fenômeno das falsas memórias, da qual a vítima expõe os fatos de modo diverso do ocorrido, também se defendendo dessa exibição desagradável.

Com isso, a vítima é exposta repetidas vezes a um fato que lhe causa grande desconforto psicológico o que pode prejudicar na obtenção de provas suficientes para ensejar uma condenação. Torna-se visível que esse sofrimento repetido da criança ou adolescente poderá afetar o seu desenvolvimento e assim, crescer de forma indigna, o que é chocante, visto a proteção 
dada pela CRFB/88 à dignidade da pessoa humana.

Diante de toda essa problemática é que se desenvolveu o projeto depoimento sem dano, da qual objetiva que a inquirição de crianças a adolescentes vítimas de violência sexual seja realizada por um profissional especializado, preferencialmente, da área da psicologia ou assistência social, com intuito de evitar que a vítima sofra repetidas vezes a inquirição, realizando uma audiência única para tomada de seu depoimento.

Percebe-se que o projeto foi proposto com o intuito de auxiliar os serventuários da justiça que não estão preparados para lidarem com essas dificuldades, já que não possuíam formação para tanto. Além disso, o fator do trabalho excessivo e diário de magistrados, promotores e advogados que lidam com variados casos, podem torná-los menos passíveis de cautela ao tratarem com vítimas psicologicamente abaladas.

Diante disso, a utilização de profissionais especializados para inquirição de crianças e adolescentes se torna mais apropriada, visto sua qualificação para lidarem com problemas psicológicos. Assim, espera-se que os especialistas sejam mais cautelosos e busquem conversar com a vítima para conhecer suas limitações e verificar se seu relato é seguro e verídico.

Sendo assim, a promulgação da atual Lei n. 13.431/17 demonstrou a preocupação do legislador em proteger os direitos inerentes as crianças e adolescentes, por estarem em fase de desenvolvimento e necessidade de maior amparo pelo Estado.

No entanto, o que realmente se espera neste momento por parte do poder judiciário é o fiel cumprimento das disposições elencadas, não somente por parte dos magistrados, mas com a preparação e contratação de profissionais especializados para tanto. Além disso, faz-se necessário mudar a estrutura dos Fóruns a fim de se adequarem com a sala especial para a realização da oitiva nos termos da lei. Assim, o estudo acerca desse 
tema deverá ser cada vez mais discutido e pesquisado.

Isso porque, observa-se que o depoimento especial traz uma solução mais eficaz para a problemática do Estado em inquirir uma criança ou adolescente vítima de violência sexual, na tentativa de evitar o máximo possível os danos secundários, além de auxiliar na coleta de provas para punir o agressor e aplicar a tão esperada justiça.

\section{REFERÊNCIAS}

AZAMBUJA, Samanta Pelizzoni de. Depoimento sem dano. 2012. Disponível em: http://www.espacovital.com.br/noticia-27463-depoimento-sem-dano. Acesso em: 18 fev. 2017.

AZEVEDO, Maria Cecília Fontes de. Depoimento sem dano: a preservação da integridade psicológica de crianças vítimas de abuso sexual. Brasília, 2013. Disponível em: http://repositorio.uniceub.br/bitstream/235/5220/1/RA20865385.pdf. Acesso em: 25 fev. 2017.

BARROS, Flaviane de Magalhães. A participação da vítima no processo penal. Rio de Janeiro: Lumen Juris, 2008.

BENJAMIN, Maria Helena Gozzer. Sistemática do projeto "depoimento sem dano" poderá ser recomendada em lei nacional. 26 nov. 2006. Disponível em: http:// www.ambito-juridico.com.br/site/?n_link=visualiza_noticia\&id_caderno=\&id_no ticia $=10380$. Acesso em: 15 fev. 2017.

BORBA, Maria Rosi De Meira. O duplo processo de vitimização da criança abusada sexualmente. Revista Jus Navigandi, Teresina, ano 7, n. 59, out. 2002. Disponível em: https://jus.com.br/artigos/3246. Acesso em: 8 fev. 2017.

BRASIL. Conselho Nacional de Justiça. Lei torna depoimento especial obrigatório em todo o país. 24 abr. 2017. Disponível em: http://www.cnj.jus.br/noticias/judiciario/84640-lei-torna-depoimento-especial-obrigatorio-em-todo-o-pais. Acesso em: 26 maio 2018.

BRASIL. Decreto-Lei n. 3.689, de 03 de outubro de 1941. Dispõe o Código de Processo Penal. Diário Oficial da República Federativa do Brasil, Rio de Janeiro, RJ, 13 out. 1941. Disponível em: http://www.planalto.gov.br/ccivil_03/decreto-lei/Del3689Compilado.htm. Acesso em: 26 mai. 2018.

BRASIL. Lei n. 8.069, de 13 de julho de 1990. Dispõe sobre o Estatuto da Criança e do Adolescente e dá providências. Diário Oficial da República Federativa do Brasil, Brasília, DF, 16 jul. 1990. Disponível em: http:/www.planalto.gov.br/ccivil_03/leis/ 18069.htm. Acesso em: 26 maio. 2018.

BRASIL. Lei n. 13.431, de 4 de abril de 2017. Estabelece o sistema de garantia de direitos da criança e do adolescente vítima ou testemunha de violência e altera a Lei n. 8.069, de 13 de julho de 1990 (Estatuto da Criança e do Adolescente). Diário Oficial 
da República Federativa do Brasil, Brasília, DF, 05 abr. 2017. Disponível em: http:// www.planalto.gov.br/ccivil_03/_ato2015-2018/2017/lei/L13431.htm. Acesso em: 26 maio 2018.

BRASIL. Superior Tribunal de Justiça. Agravo Regimental Em Recurso Especial. Rel. Ministro Reynaldo Soares Da Fonseca. AgRg no REsp 1774080/RS. Quinta Turma, Julgado em 07 fev. 2019, DJe 15 fev. 2019. Disponível em: http://www.stj.jus.br/ SCON/jurisprudencia/toc.jsp?livre=CRIME+SEXUAL+PALAVRA+DA+V\%CDTI$\mathrm{MA}+\mathrm{MENOR} \& \mathrm{~b}=\mathrm{ACOR} \&$ thesaurus $=J U R I D I C O \& p=$ true. Acesso em: 18 abr. 2019.

BRITO, Leila Maria Torraca de. Depoimento sem dano, para quem? In: Observatório jovem. 07 maio 2008. Disponível em: http://www.uff.br/observatoriojovem/materia/ depoimento-sem-dano-para-quem. Acesso em: 15 fev. 2017.

CASTRO, Myriam Mesquita Puguese de. ECA comentado: artigo 5/Livro 1: tema: criança e adolescente. Promenino Fundação Telefônica, 2008. Disponível em: http:// www.promenino.org.br/noticias/arquivo/eca-comentado-artigo-5-livro-1 - -tema-crianca-e-adolescente. Acesso em: 17 nov. 2016.

CEZAR, José Antônio Daltoé. Depoimento sem dano: uma alternativa para inquirir crianças e adolescentes nos processos judiciais. Porto Alegre: Livraria do Advogado, 2007.

CEZAR, José Antônio Daltoé. Projeto depoimento sem dano: direito ao desenvolvimento sexual saudável. Associação dos Magistrados Brasileiros. 2008. Disponível em: http://www.asppe.org/index_arquivos/projeto_depoimento_sem_dan o.pdf. Acesso em: 25 fev. 2017.

DEEKE, Nathália. Valoração da prova testemunhal e do depoimento da criança nos crimes de abuso sexual. JusBrasil, 29 fev. 2016. Disponível em: https://nathaliadeeke. jusbrasil.com.br/artigos/309503209/valoracao-da-prova-testemunhal-e-do-depoimento-da-crianca-nos-crimes-de-abuso-sexual. Acesso em: 18 abr. 2019.

DIGIÁCOMO; Murillo José; DIGIÁCOMO, Eduardo. Comentários à lei n. 13.431/2017. Curitiba: Ministério Público do Estado do Paraná, 2018.

DOBKE, Veleda. Abuso sexual: a inquirição das crianças uma abordagem interdisciplinar. Porto Alegre: Ricardo Lenz Editor, 2011.

GABEL, Marceline. Crianças vítimas de abuso sexual. Tradução de S. Goldfeder \& M.C.C. Gomes. São Paulo: Summus Editorial, 1997.

GONÇALVES, Hebe Signorini; BRANDÃO, Eduardo Ponte. (org.). Psicologia jurídica no Brasil. 3. ed. Rio de Janeiro: Nau, 2015.

GONÇALVES, Victor Eduardo Rios. Direito processual penal esquematizado. 7 ed. São Paulo: Saraiva, 2018.

HABIGZANG, Luísa F.; KOLLER, Silvia H.; AZEVEDO, Gabriela Azen; MACHADO, Paula Xavier. Abuso Sexual Infantil e Dinâmica Familiar: aspectos observados em processos jurídicos. Revista Psicologia: Teoria e Pesquisa, v. 21, n. 3, set./dez. 2005. Disponível em: http://www.scielo.br/pdf/\%0D/ptp/v21n3/a11v21n3.pdf. Acesso em: 08 fev. 2017.

LIMA, Renato Brasileiro de. Manual de processo penal: volume único. 6. ed. rev. ampl. e atual. Salvador: Juspodivm, 2018. 
MACHADO, Lauro. As vítimas e os direitos humanos. Pub. 09 fev. 2016. Disponível em: http://www.opopular.com.br/editorias/opiniao/opini\%C3\%A3o-1.146391/as-v\%C3\%ADtimas-e-os-dire itos-humanos-1.1034885. Acesso em: 06 fev. 2017.

MASI, Carlo Velho. Falsas memórias no processo penal. Canal Ciências Criminais, 25 jul. 2015. Disponível em: https://canalcienciascriminais.com.br/falsas-memoriasno-processo-penal-parte-1/. Acesso em: 10 fev. 2017.

MENEGAZZO, André Frandoloso. Depoimento sem dano: inquirição de crianças e adolescentes vítimas de abuso sexual. Revista Jus Navigandi, Teresina, ano 16, $\mathrm{n}$. 2854, 25 abr. 2011. Disponível em: https://jus.com.br/artigos/18930. Acesso em: 25 fev. 2017.

MÖLLER, Daniela; DINIZ, Tânia Maria Ramos de Godoi. Nota técnica sobre o exercício profissional de assistentes sociais e as exigências para a execução do depoimento especial. Brasília, Conselho Federal de Serviço Social, 2018.

MOROTTI, Carlos. Vitimização primária, secundária e terciária. In: JusBrasil, 2015. Disponível em: https://morotti.jusbrasil.com.br/artigos/210224182/vitimizacao-primaria-secundaria-e-terciaria . Acesso em: 18 abr. 2019.

NIZA, Angélica Soares; SILVA, Marcos Antonio Duarte. Vitimologia no processo penal sob a ótica dos direitos humanos. Boletim Jurídico, Uberaba/MG, ano 13, n. 1544, 2018. Disponível em: https://www.boletimjuridico.com.br/ doutrina/artigo/4677/vitimologia-processo-penal-sob-otica-direitos-humanos. Acesso em: 18 abr. 2019.

OLIVEIRA, Vera Cristina Pereira de Souza Azevedo. Considerações sobre a criança e o adolescente diante da Justiça nos crimes de abuso sexual infantil. In: VOLNOVICH, Jorge R. (org.). Abuso sexual na infância. Rio de Janeiro: Lacerda, 2005.

POTTER, Luciane; BITENCOURT, Cezar Roberto (org.). Vitimização secundária infanto-juvenil e violência sexual intrafamiliar: por uma política pública de redução de danos. Rio de Janeiro, 2009.

QUEIROZ, Maria Isabel. Vitimização terciária. In: JusBrasil, 2019. Disponível em: https://mariaisabelqueiroz.jusbrasil.com.br/artigos/663339094/vitimizacao-terciaria. Acesso em: 18 abr. 2019.

RIBEIRO, Francisco Sidney de Castro. Apalavra da vítima no processamento dos crimes sexuais. Revista Pesquisas Jurídicas, v. 1, n. 1, p. 95-96, jul./dez. 2012. Disponível em: http://www.revistapesquisasjuridicas.com.br/ojs/index.php/RPJur/article/ view/7. Acesso em: 31 jan. 2017.

ROQUE, Emy Karla Yamamoto. A justiça frente ao abuso sexual infantil: análise crítica ao depoimento sem dano e métodos alternativos correlatos. 2010. Dissertação (Mestrado em Direito) - Fundação Getúlio Vargas, Rio de Janeiro, 2010.

SEGER, Mariana da Fonseca. Prova testemunhal e processo penal: a fragilidade do relato a partir da análise da subjetividade perceptiva e do fenômeno das falsas memórias. Monografia (Graduação em Direito) - Pontifícia Universidade Católica, Porto Alegre, 2012. Disponível em:http:/www3.pucrs.br/pucrs/files/uni/poa/direito/graduacao/tcc/tcc2/trabalhos2012_2/mariana_seger.pdf. Acesso em: 10 fev. 2017.

SOUSA, Meirelene Martins Araújo de. A importância do depoimento sem dano na produção de provas nos crimes praticados contra crianças e adolescentes. In:Web Artigos, 11 jul. 2012. Disponível em: http://www.webartigos.com/artigos/a- 
importancia-do-depoimento-sem-dano-na-producao-de-provas-nos-crimes-praticadoscontra-criancas-e-adolescentes/92325/. Acesso em: 18 fev. 2017.

STEIN, Lilian Milnitsky. Falsas memórias: fundamentos científicos e jurídicos e suas aplicações clínicas e jurídicas. Porto Alegre: Artmed, 2010.

TABAJASKI, Betina; PAIVA, Cláudia Victolla; VISNIEVSKI, Vanea Maria. Um novo olhar sobre o testemunho infantil. In: POTTER, Luciane (org.). Depoimento sem dano: uma política criminal de redução de danos. Rio de Janeiro: Lumen Juris, 2010.

TOURINHO FILHO, Francisco da Costa. Manual de processo penal. 13. ed. São Paulo: Saraiva, 2010.

TRINDADE, Jorge. Manual de psicologia jurídica para operadores de direito. 3 . ed. Porto Alegre: Livraria do Advogado, 2009.

TRINDADE, Jorge. Manual de psicologia jurídica para operadores do direito. 7. ed. rev. atual. e ampl. Porto Alegre: Livraria do Advogado, 2014.

Recebido em: 18/04/2019

Aprovado em: 17/06/2019 